\title{
Predictors of Sensitivity in Mothers of 8-Month-Old Infants ${ }^{1}$
}

\author{
Patrícia Alvarenga ${ }^{2}$ \\ Maria Virginia Machado Dazzani \\ Eulina da Rocha Lordelo \\ Universidade Federal da Bahia, Salvador-BA, Brazil \\ Cristiane Ajnamei dos Santos Alfaya \\ Universidade Federal do Recôncavo da Bahia, Santo Antonio de Jesus-BA, Brazil \\ Cesar Augusto Piccinini \\ Universidade Federal do Rio Grande do Sul, Porto Alegre-RS, Brazil
}

\begin{abstract}
This longitudinal study investigated the impact of maternal mental health, including postpartum depression, and of maternal-fetal attachment, on maternal sensitivity when babies were eight months old. The study included 38 mother-infant dyads. The women answered the SRQ-20 and the Maternal-Fetal Attachment Scale in the third trimester of pregnancy, and the BDI, for evaluation of postpartum depression in the first month following birth. Maternal sensitivity was examined through an observation of mother-child interaction when babies were eight months old. The multiple regression model considering the three factors explained $18.6 \%$ of the variance in sensitivity, and only maternal-fetal attachment was a significant predictor. The results indicate the importance of interventions to promote the bond of pregnant women with their babies, which may even minimize possible harmful effects of postpartum depression on mother-child interaction.
\end{abstract}

Keywords: pregnancy, mental health, major depression, mother-child relations

\section{Preditores da Responsividade Materna no Oitavo Mês de Vida do Bebê}

\begin{abstract}
Resumo: Este estudo longitudinal teve por objetivo investigar o impacto da saúde mental da mãe, incluindo a depressão pósparto, e do apego materno-fetal sobre a responsividade materna no oitavo mês de vida do bebê. Participaram do estudo 38 díades mãe-bebê. As gestantes responderam o SRQ-20 e a Escala de Apego Materno-Fetal no terceiro trimestre da gestação, e o BDI, para avaliação da depressão pós-parto, no primeiro mês de vida do bebê. A responsividade materna foi examinada por meio de uma sessão de observação da interação mãe-criança no oitavo mês de vida do bebê. O modelo de regressão múltipla, considerando os três fatores, explicou $18,6 \%$ da variância na responsividade, sendo que apenas o apego materno-fetal foi um preditor significativo. Os resultados indicam a importância de intervenções que favoreçam o vínculo da gestante com o bebê, que poderão, inclusive, minimizar possíveis efeitos deletérios da depressão pós-parto sobre a interação mãe-criança.
\end{abstract}

Palavras-chave: gravidez, saúde mental, depressão, relações mãe-criança

\section{Predictores de la Sensibilidad Materna a los Ocho Meses del Bebé}

\begin{abstract}
Resumen: Este estudio longitudinal investigó el impacto de la salud mental materna, incluso la depresión post-parto, y del apego materno-fetal, en la sensibilidad materna en el octavo mes de vida del bebé. El estudio incluyó a 38 díadas madre-niño. Las mujeres respondieron al SRQ-20 y a la Escala de Apego Materno-Fetal en el tercer trimestre del embarazo, y al BDI, para la evaluación de la depresión en el primer mes después del nacimiento. La sensibilidad materna fue examinada mediante la observación de la interacción madre-hijo en el octavo mes del bebé. El modelo de regresión múltiple, teniendo en cuenta los tres factores, explicó el 18,6\% de la variación en la sensibilidad materna, y sólo el apego materno-fetal fue un predictor significativo. Los resultados indican la importancia de las intervenciones para promover la unión de la mujer embarazada con el bebé, pudiendo incluso minimizar los posibles efectos nocivos de la depresión post-parto en la interacción madre-hijo.
\end{abstract}

Palabras clave: embarazo, salud mental, depresión, relaciones madre-niño

Mother-child interaction in the first year of life has been emphasized in the literature as a fundamental phenomenon to understand differences in developmental outcomes in the cognitive, affective and social domains (Fraley, Roisman, \& Haltigan, 2013; Vandell et al., 2010). The pioneers of

\footnotetext{
1 Acknowledgment: The authors are grateful to the students who helped with data collection and analysis, and to all mothers who participated. Support: Fundação de Amparo à Pesquisa do Estado da Bahia (FABESP).

${ }^{2}$ Correspondence address:

Patrícia Alvarenga. Departamento de Psicologia. Universidade Federal da Bahia. Rua Aristides Novis, 197, Federação. CEP 40210-730. Salvador-BA, Brazil. E-mail: palvarenga66@gmail.com
}

Attachment Theory (Ainsworth, Blehar, Waters, \& Wall, 1978; Bowlby, 1969) proposed concepts that characterize and organize the essential aspects of mother-infant interaction, which are necessary to understand its influence on infant development, including maternal sensitivity.

More recently, the concepts of maternal responsiveness (Bornstein, Tamis-LeMonda, Hahn, \& Haynes, 2008; Ribas, Moura, \& Ribas Junior, 2003) or sensitivity (Cerezo, Trenado, $\&$ Pons-Salvador, 2012) have been used to designate parental characteristics that are desirable and necessary to establish a safe attachment pattern between infants and their caregivers, consequently favoring the exploration of the environment, 
affective bonding and interpersonal relationships in general. Isabella, Belsky and von Eye (1989) define maternal sensitivity as consistent attention and perception, accurate interpretation and contingent and appropriate response to the infant's signals. As maternal response is contingently related to infants' signs, they indicate to the child that his/ her interests and needs are important and that signaling them will result in positive and predictable responses by the mother or caregiving adult (Landry, Smith, Swank, \& Guttentag, 2008).

While sensitive mothers tend to put themselves in the infants' place and respond to their needs in a sensitive manner, less sensitive mothers would tend to interact with the infant based on their own internal conditions and general notions about infant functioning, besides other factors that are but weakly related to infants' specific emotional and physical needs (Koren-Karie, Oppenheim, Dolev, Sher, \& Etzion-Carasso, 2002). A very satisfactory consensus is shown in the literature, indicating that high maternal sensitivity is associated with secure attachment, while low maternal sensitivity is associated with insecure attachment patterns (Cerezo et al., 2012; Moran, Forbes, Evans, Tarabulsy, \& Madigan, 2008). Although this concept is predominantly linked with mother-infant interaction in the literature, it can also be applied to the infant's interaction with other attachment figures, like the father, or other people in parental functions (Lucassen et al., 2011).

Some authors have emphasized the multidimensional nature of the maternal sensitivity concept. According to Wakschlag and Hans (1999), sensitivity is not a single construct, but a domain that comprises a complex of constructs and related variables, including sensitivity to social cues, empathy, forecasting ability, non-intrusiveness, emotional availability and positive involvement. In the same sense, other authors point to the need to consider a broad system of reference and associated variables in research (Bornstein et al., 2008) and, on the other hand, also highlight that, depending on how sensitivity is assessed or measured, different developmental results can be obtained with regard to this dimension of maternal conduct (Grusec \& Davidov, 2010).

While researchers have substantially focused on the effects of maternal sensitivity on child development, studies about its predictors are less numerous. Among the multiple maternal variables which have been shown to be associated with maternal sensitivity, the variables investigated in this study are emphasized here, that is, maternal-fetal attachment and symptoms of mental disorders, particularly postpartum depression.

Maternal-fetal attachment, defined as the extent to which women engage in behaviors that indicate bonding and interaction with the infant during pregnancy (Cranley, 1981), has been related with maternal sensitivity in some studies. In the research by Shin, Park e Kim (2006), maternalfetal attachment was the strongest predictor of maternal sensitivity in infants' first weeks of life, explaining about $31 \%$ of variance. Similarly, Siddiqui and Hagglof (2000) assessed the relations between maternal-fetal attachment and maternal sensitivity during mother-infant interaction in the $12^{\text {th }}$ week of life. The study results also showed the impact of different factors in the Prenatal Attachment Inventory (PAI) on maternal sensitivity. To give an example, mothers who scored higher on the factor "fantasy" in the PAI showed more involvement while interacting, with higher frequencies of stimulating behaviors and reactions to the infant's behaviors. In addition, mothers with high scores for the "interaction and affection" factor used more proximal stimulation strategies, while mothers who scored higher on "differentiation of self from fetus" used more distal stimulation. Anyway, the only predictor of the interactive dimension called "maternal response", defined as maternal behaviors performed in reaction to infant behaviors, was attentive infant behavior during the interaction. No relation was found between maternal response and PAI factors. Other studies indicate the impact of maternal-fetal attachment on maternal behavior, although they do not directly and explicitly assess the sensitivity variable, but other correlated constructs or that refer to maternal behavior towards the infant, such as healthy practices during pregnancy (Alhusen, Gross, Hayat, Woods, \& Sharps, 2012), maternal role competence (Mercer \& Ferketich, 1994) and early mother-infant attachment in the postpartum period (Shin, Park, \& Kang, 2004).

Despite this evidence, no consistent results are presented in the literature about the association between maternal-fetal attachment and maternal behavior after the infant's birth, which can be partially explained by difficulties to assess these constructs, besides theoretical divergences. To give an example, Thun-Hohenstein, Wienerroither, Schreuer, Seim and Wienerroither (2008) assessed the affective bond between mother and fetus, using a questionnaire about maternal representations regarding the infant. In addition, in the third month of life, the interaction between mother and infant was recorded. The results did not reveal any significant association among the research factors though. Only a weak correlation was found between the mental representation score about the fetus and general maternal regulatory capacity, related to the notion of interactional synchrony. It is important to remind here that, although the questionnaire about maternal representations regarding the infant assesses dimensions that are very similar to those investigated by instruments that evaluate maternal-fetal attachment, the concept of maternal sensitivity is not explicitly applied in the study.

As regards the effects of mental health, and more specifically of pre and postpartum maternal depression on sensitivity, the findings are also controversial. It is important to highlight that, in the present study as well as in the literature reviewed, the term "maternal mental health" relates to the presence or absence of anxiety and depression symptoms, detected through psychiatric screening or clinical diagnostic 
instruments, applied in the pre or postpartum periods. In that perspective, the notion of minor psychiatric disorders should be highlighted. According to Santos (2002), that concept refers to the health condition of a population with individuals who do not attend to formal depression or anxiety criteria according to the DSM-IV (Diagnostic and Statistical Manual of Mental Disorders - Fourth Edition) and ICD-10 (International Classification of Diseases $-10^{\text {th }}$ Revision), but who present a functional disability that is comparable with or even worse than well-established chronic conditions.

While some studies indicate relations between maternal depression symptoms and low sensitivity (Belsky \& Fearon, 2002; Huang, Lewin, Mitchell, \& Zhang, 2012; Waxler, Thelen, \& Muzik, 2011), in two systematic literature reviews, the relevance of this relation is questioned, at least with regard to some of the dimensions of maternal behavior. The review by Lovejoy, Graczyk, O'Hare and Neuman (2000) involved a meta-analysis of 46 observational studies on maternal behaviors while interacting with the infant and their relations with depression symptoms. According to the authors, a strong association was found for negative maternal behaviors (hostility, intrusiveness and coercion), and there were also some evidences for disengaged maternal behavior, although they were not strong. As regards positive maternal behaviors, however, little influence of depression was found. In a more recent review about the relation between maternal psychopathology and attachment patterns, Wan and Green (2009) affirm that the relations between depression and insecure attachment (which in turn is related to low maternal sensitivity) are inconsistent. Those authors point to the need for further research about the effect of mediating and moderating variables. Studies about the relations between maternal anxiety symptoms and sensitivity are scarcer. Nicol-Harper, Harvey and Stein (2007) compared mother-infant interaction in a group of mother-infant dyads whose mothers revealed high trait-anxiety and another with mothers showing low trait-anxiety. Mother-child interaction was assessed when the infants were between ten and 14 months of life. The results indicated that the mothers in the group with high trait-anxiety demonstrated lower levels of sensitivity while interacting with the infants. Finally, Alvarenga, Dazzani, Alfaya, Lordelo and Piccinini (2012) and Schmidt and Argimon (2009) found relations between depression symptoms and anxiety during pregnancy and lower levels of maternal-fetal attachment.

Other maternity-related variables have been investigated as predictors of sensitivity, which were shown to influence that factor, including the mother's personality (Prinzie, Stams, Dekovic, Reijntjes, \& Belsky, 2009), social support and the relation with the child's father (Piccinini, Marin, Alvarenga, Lopes, \& Tudge, 2007; Shin et al., 2006), self-esteem (Shin, Park, Ryu, \& Seomun, 2008) and identification with the infant (Shin et al., 2008). Finally, it is important to highlight that infant-related variables like irritability or negative affect (Mills-Koonce et al., 2007) for example, or even the child's gender (Thun-Hohenstein et al., 2008), can also influence maternal sensitivity and should be investigated, but go beyond the scope of the present study.

According to Shin et al. (2006), research on predictors of maternal sensitivity in recent decades which include regression analysis are able to explain between 12 and $19 \%$ of variance in this factor, which is considered low. In addition, many studies adopt self-reporting instruments to assess maternal sensitivity and do not provide observational data regarding mother-infant interaction. Also, most of the studies do not involve longitudinal designs. That is an important methodological limitation in this area, as the instruments are often based on retrospective data.

Thus, the aim in this longitudinal research was to investigate the impact of the mother's mental health, including postpartum depression, and of maternal-fetal attachment on maternal sensitivity in the eighth month of the infant's life. The main hypothesis was that, the higher the maternal-fetal attachment scores and the lower the scores of minor psychiatric disorders during pregnancy and of postpartum depression, the greater the maternal sensitivity would be at eight months.

\section{Method}

\section{Participants}

The study participants were 38 mother-infant dyads, selected by convenience at four public maternities in Salvador City, Bahia, Brazil. The infants, born full term and in good health conditions, were all male. The characteristic is due to the fact that the study sample is part of a longitudinal project that investigates predictors of antisocial behavior in childhood. As the literature indicates that boys more frequently present externalizing and antisocial behaviors, the choice was made to select only male children for the study. The mothers were between 18 and 39 years old $(M=29.00 ; S D=5.61)$ and had reached the third trimester of pregnancy during the first data collection phase, when the sociodemographic information was collected. The pregnant woman $(M=10.84 ; S D=2.17)$ and the infant's father $(M=10.83 ; S D=2.17)$ had similar education levels, showing unfinished or finished secondary education in most of the sample. While most pregnant women did not have a paid job $(66 \%)$, most fathers were formally employed (87\%). Although the sample was taken from a low-income population, the mean number of children per pregnant woman was low $(M=0.84 ; S D=1.05)$. As regards the family income, the mean amount was $\mathrm{R} \$ 930.08(S D=627.82)$, equivalent to 1.5 minimum wages. Most women lived with the infant's father (82\%). Most participants $(89 \%)$ did not suffer any health problems while pregnant. The infants' mean birth weight was $3.403 \mathrm{~kg}(S D=427.34 \mathrm{~g})$ and the mean size was $49.76 \mathrm{~cm}(S D=4.62 \mathrm{~cm})$. Table 1 displays details of the participants' sociodemographic data. 
Table 1

Sociodemographic Characteristics of the Participants $(n=38)$

\begin{tabular}{lc}
\hline Pregnant woman's age & $M=29.00(S D=5.61)$ \\
Pregnant woman's educational level & $M=10.84(S D=2.17)$ \\
(in years) & \\
Educational level of infant's father & $M=10.83(S D=2.17)$ \\
(in years) & \\
Pregnant woman's occupation & $34 \%$ \\
Have a paid job & $66 \%$ \\
Do not have a paid job & \\
Occupation of infant's father & $87 \%$ \\
Have a paid job & $13 \%$ \\
Do not have a paid job & $M=0.84(S D=1.05)$ \\
Number of children & $M=48.79(S D=56.02)$ \\
Time of marital union (in months) & \\
Pregnant woman's health problems & $11 \%$ \\
Yes & $89 \%$ \\
No & \\
Does the pregnant woman live with & \\
the infant's father? & \\
Yes & \\
No & \\
Family income & \\
& $(S D=\mathrm{R} \$ 627,82)$ \\
\hline
\end{tabular}

\section{Instruments}

The following instruments were used:

Form with Pregnant Woman's Sociodemographic and Health Data: Used to investigate data like the pregnant woman's age, education, profession, marital status, existence of other children, health condition during pregnancy and expected birth date.

Maternal-fetal Attachment Scale: This scale was used to assess the mother's attachment with the fetus. The instrument contains 24 items, divided into five subscales that represent different aspects of this relation. Examples of scale items include: "I talk to my baby" and "I imagine myself feeding/ breastfeeding the baby". For each item, five alternative answers are offered on a Likert scale, ranging from "definitely yes" to "definitely no". The internal consistency (Cronbach's alpha) coefficient of the complete original scale is .85; in the Brazilian validation, the coefficient corresponded to .63 (Feijó, 1999). The sum of item scores provides the total maternalfetal attachment score, which can range from zero to 96.

SRQ-20 (Self-Report Questionnaire of Minor Psychiatric Disorders): This psychiatric screening scale consists of 20 items to detect non-psychotic symptoms of minor or common psychiatric disorders, with yes/no answers. The internal consistency coefficient (Cronbach's alpha) of the Brazilian version corresponded to .86 (Gonçalves, Stein, \& Kapczinski, 2008). The sum of items with "yes" answers corresponds to the total scale score, with a possible range from zero to 20 . The higher the score, the greater the probability of some minor psychiatric disorders.
Beck Depression Inventory - BDI: This instrument is a symptomatic self-reporting scale, including 21 items with different alternative answers about how the individual has felt recently, which correspond to different depression severity levels. The sum of the individual scores reveals a total score, representing a dimensional score of the depression intensity, which can be classified as follows: minimal, mild, moderate or severe. The total score can range from zero to 63 points. For the sake of this study, the Portuguese version of the inventory was used (Cunha, 2001), with an internal consistency coefficient of .84 .

Observation of Mother-Infant Interaction $-8^{\text {th }}$ month: Used to assess maternal sensitivity. The mother was filmed during 10 minutes while interacting with the infant, using three toys provided by the researchers: a rattle, a toy with colored buttons that made sounds when pressed and a toy with rings, colored buttons and a mirror. The three initial and final minutes of each film were analyzed, using 12-second intervals, based on categories described in the literature (Bornstein et al., 2008; Piccinini, Alvarenga, \& Frizzo, 2007). During the first six seconds, the infant's behaviors were registered in three distinct categories: smiles (the infant smiles visibly, also including smiles not directed at the mother); vocalizes (the infant babbles or moves his mouth, attempting to vocalize or imitate maternal vocalization, also including vocalizations of protest and "laughs"); and cries/ whines (the infant is visibly uncomfortable, restless and/ or cries, also including continuous and strong crying). The maternal responses to these behaviors were registered during the same and the subsequent (six-second) interval in ten distinct categories: interprets/talks for the infant (the mother vocalizes, empathetically putting herself in the infant's place, interpreting the infant's condition and/or signals); talks to the infant (exclusively refers to the mother's expressions, whose contents did not involve the game; the mother vocalizes, talking with the infant, imitating his vocalizations, singing for him or making sounds); smiles to the infant (the mother smiles, looking at the infant and both are on the same visual plane); takes on the knees/wraps/cuddles (the mother holds the infant on her lap and/or rocks the infant in her arms or on her legs; holds the infant close to her body); caresses/kisses the infant (the mother touches the infant's body or face with her fingers/hand or face, caressing him; the mother kisses the infant); touches/physically stimulates/stimulates with an object (the mother touches the infant with parts of her body to stimulate him or makes gestures with or without the help of objects/toys to attract the infant's attention); offers the toy (the mother catches a toy and offers it to the infant, putting it in his hand, on his body or near the infant's hand); describes the toy, activity or event (the mother describes characteristics or attributes adjectives to the toys); cues/ stimuli to play (mother encourages infant through orders or suggestions to play); asks questions about the toy or activity (mother asks questions about the toys and activities the infant is doing with or without toys). All mother and infant 
behaviors were registered, considering that the recorded behaviors are not mutually exclusive. Two independent coders analyzed the mother-infant interaction, who received considerable training. Reliability was established based on 12 videos and corresponded to a mean coefficient of .79 for the maternal behavior categories and .77 for the infant behavior categories (Cohen's Kappa coefficient). In the second analysis phase, the three infant behaviors under analysis (smiles, vocalizes and cries/weans) were combined with the ten maternal behavior categories, constituting the so-called sensitive sequences. The three infant behaviors combined with the absence of maternal response corresponded to the non-sensitive sequences. Thus, 30 sensitive and three nonsensitive sequences were derived. For each of the sequences, the percentage of sensitive or non-sensitive sequences was calculated, dividing the number of events in that sequence by the number of infant behaviors. To give an example, for the sequence smiles - interprets/talks for the infant, the percentage of infant smiles the mother responded to by interpreting or talking to the infant was calculated dividing the frequency in this category (smiles - interprets/talks for the infant) by the frequency in the infant smile category. This procedure was adopted to control for the effect of the infant's number of behaviors during the six minutes analyzed on maternal sensitivity. This avoided that mothers of more active infants, that is, who gave more frequent cues during the observation period, would be considered more sensitive for that reason. The total percentage of sensitive sequences was used as a general maternal sensitivity score.

\section{Procedure}

Data collection. During the third trimester of pregnancy, the pregnant women were invited to participate in the research and individually answered a form with sociodemographic and health data, the Maternal-Fetal Attachment Scale and the SRQ-20 to assess indicators of minor psychiatric disorders. When the infants completed one month of life, the families received a home visit, when the mothers individually answered the BDI. Finally, during the infant's eighth month of life, a new home visit was scheduled to observe the Mother-Infant- $8^{\text {th }}$ Month Interaction, used to assess maternal sensitivity. The observation was filmed.

Data analysis. The data were initially submitted to descriptive and correlational statistic procedures. In the second analysis phase, the three predictive variables (maternal-fetal attachment score, minor psychiatric disorders score and postpartum depression score) and the predicted variables (percentage of sensitive sequences and percentage of non-sensitive sequences) were included in multiple regression analyses.

\section{Ethical Considerations}

This study is part of a longitudinal project that complies with all ethical guidelines for research involving human beings in Brazil. Approval was obtained from the Ethics Committee at the School of Philosophy and Human Sciences, Universidade Federal da Bahia (Salvador/BA), Brazil.

\section{Results}

Initially, the minima and maxima, means, standard deviations and confidence intervals (95\%) were calculated for the predictive variables and the mean percentages of the sensitive and non-sensitive sequences (predicted variables). The SRQ-20 scores ranged between 2 and 15 $(M=8.24 ; S D=0.52 ; C I=7.17$ - 9.30). On the MaternalFetal Attachment Scale, the mothers scored between 73 and $108(M=92.63 ; S D=1.25 ; C I=90.08$ - 95.18). The BDI scores varied between 1 and $43(M=13.13 ; S D=1.30$; $C I=10.50$ - 15.77). As regards the sensitive and non-sensitive sequences, the mean percentages, standard deviations and confidence intervals are displayed in Table 2.

Table 2

Mean, Standard Deviation and Confidence Interval of Sensitive and Non-Sensitive Sequences $(n=38)$

\begin{tabular}{lccc}
\hline Sequences & Mean & $S D$ & $C I$ \\
\hline Sensitive sequences/smiling & 1.62 & 1.19 & $1.23-2.01$ \\
Sensitive sequences/vocalizations & 1.29 & 0.17 & $0.93-1.64$ \\
Sensitive sequences/crying & 0.51 & 0.16 & $0.17-0.84$ \\
Total sensitive sequences & 1.78 & 0.10 & $1.56-2.00$ \\
Non-sensitive sequences/smiling & 0.84 & 0.03 & $0.01-0.15$ \\
Non-sensitive sequences/vocalizations & 0.13 & 0.02 & $0.08-0.19$ \\
Non-sensitive sequences/crying & 0.006 & 0.004 & $0.003-0.01$ \\
Total non-sensitive sequences & 0.11 & 0.02 & $0.07-0.16$ \\
\hline
\end{tabular}

The participants' scores on the SRQ-20, on the maternalfetal attachment scale and on the BDI were correlated with the percentages of sensitive and non-sensitive sequences, involving the infants' smiles, vocalizations and crying, besides the total percentages of sensitive and non-sensitive sequences. Table 3 displays the results of Pearson's Correlation Test.

Table 3

Correlations Between Maternal-Fetal Attachment (MFA), Minor Psychiatric Disorders (MPD), Postpartum Depression (PPD) and Sensitive and Non-Sensitive Sequences $(n=38)$

\begin{tabular}{lccc}
\hline Sensitivity & MFA & MPD & PPD \\
\hline Sensitive sequences/smiling & $.37^{*}$ & .05 & -.47 \\
Sensitive sequences/vocalizations & .22 & -.17 & -.14 \\
Sensitive sequences/crying & .06 & .03 & -.10 \\
Total sensitive sequences & $.48^{* *}$ & -.13 & -.10 \\
Non-sensitive sequences/smiling & -.13 & -.08 & -.07 \\
Non-sensitive sequences/vocalizations & -.25 & $.31^{*}$ & -.22 \\
Non-sensitive sequences/crying & .13 & .16 & .12 \\
Total non-sensitive sequences & -.25 & .21 & -.47 \\
\hline
\end{tabular}

${ }^{*} p<.05 .{ }^{* *} p<.01$. 
The results revealed a positive correlation $(r=.37$; $p<.05)$ between the maternal-fetal attachment score and the percentage of sensitive sequences involving the infants' smiles, and a positive correlation $(r=.48 ; p<.01)$ between the maternal-fetal attachment score and the total percentage of sensitive sequences. Both correlations indicate that the stronger the maternal-fetal attachment during pregnancy, the greater the sensitivity will be in the infant's eighth month of life. In addition, a positive correlation was found between the total SRQ-20 score and the percentage of non-sensitive sequences involving the infants' vocalizations $(r=.31 ; p<.05)$, indicating that the larger the number of indicators of minor psychiatric disorders during pregnancy, the higher the percentage of nonsensitive sequences involving the infants' vocalizations during the eighth month of life.

A multiple linear regression analysis was developed, including the three predictive variables and the total percentage of sensitive sequences. Table 4 displays the results of that regression analysis.

Table 4

Multiple Regression Analysis of Sensitive Sequences in Relation to Maternal-Fetal Attachment. Minor Psychiatric Disorders and Postpartum Depression $(n=38)$

\begin{tabular}{lccc}
\hline Predictive factors & $B$ & SE Beta & $p(\mathrm{~T})$ \\
\hline Maternal-fetal attachment & .04 & .48 & .003 \\
Minor psychiatric disorders & -.009 & -.04 & .78 \\
Postpartum depression & -.01 & -.12 & .43 \\
\hline
\end{tabular}

$F=3.82 . p=.01$.

According to the results, there were no signs that the pregnant women's mental health and maternal depression could explain the percentages of sensitive sequences at the age of eight months. On the other hand, for each additional point on the maternal-fetal attachment scale, the total percentage of sensitive sequences increased by .042 when the other variables in the model were kept constant $(p=.003)$. The multiple regression model $(F=3.82, p=.01)$ in which the three analytic factors were considered explained $18.6 \%$ of total variance in the percentage of sensitive sequences. The same procedure was adopted for the percentage of non- sensitive sequences, but none of the three predictors explained a considerable portion of variance in that factor.

\section{Discussion}

The present study results partially support the hypothesis that, the higher the maternal-fetal attachment scores and the lower the minor psychiatric disorders and postpartum depression scores, the greater the maternal sensitivity level will be in the eighth month of the infants' lives. Although the correlation analysis indicates the role of minor psychiatric disorders in one of the maternal sensitivity categories, the variance explained through the regression analysis was basically associated with maternal-fetal attachment. The literature review already demonstrated a relation between these variables, revealing that maternal-fetal attachment was the variable with the highest predictive power $(31 \%)$ of sensitivity when compared to social support, maternal identification and socio-demographic variables (Shin et al., 2006).

These results indicate the importance of the mother's relation with her infant during pregnancy and the relevance of changes in the woman's identity and behavior during the transition process towards motherhood. In the literature, the personal transformations women go through during that period are highlighted (Stern, 1997), although few studies provided evidence to show the long-lasting consequences of these prenatal aspects, like maternal-fetal attachment, for example, as suggested in the present study. These findings also support the ideas by Mercer (2004) that difficulties in the first phase of the transition to motherhood, corresponding to the pregnant woman's commitment and attachment to the future infant, tend to entail persistent and potentially harmful implications. In addition, there is evidence that the development of an affective bond with the fetus during pregnancy serves as a protective factor against postpartum depression (Brandon, Pitts, Denton, Stringer, \& Evans, 2009). This can explain, at least partially, the fact that maternal depression indicators in this study were not correlated with the maternal sensitivity indicators. In that sense, one may think that a strong maternalfetal bond can contribute to mitigate the consequences of postpartum depression for mother-infant interaction, at least during the first year of the infant's life.

It is also interesting to observe that, among the three types of sensitive sequences investigated, the type that was positively correlated with maternal-fetal attachment involved the infant's smiles, indicating that the greater the maternalfetal attachment, the more the mother gave sensitive responses to the infant's smiles during the interaction. Although this was not repeated with the same degree of intensity for the sequences involving infants' vocalizations or crying, these categories may also have contributed to the significant correlation found between maternal-fetal attachment and the total number of sensitive sequences. Anyway, this finding about the sensitive sequences that involve smiling is riveting and suggests that stronger attachment with the fetus during pregnancy could make the mother more susceptible and responsive to the infant's smile, which is an important early indicator of socio-emotional development (Landry, Smith, Swank, Assel, \& Vellet, 2001).

Thus, the present study findings underline the importance of interventions that help the mothers in their relations with the fetus during pregnancy, and that particularly favor maternal-infant attachment. Besides support groups for pregnant women and specific parenthood support programs, simple measures like echograms (Yarcheski, Mahon, Yarcheski, Hanks, \& Cannella, 2009) and mental health care for women of fertile age (Alvarenga et al., 2012) can benefit prenatal bonding between mother 
and fetus. Also, including intervention strategies that are more directly focused on the emotional demands of pregnancy can be a promising strategy. The study by Piccinini, Carvalho, Ourique and Lopes (2012), in which the pregnant women's perceptions and feelings about prenatal care were investigated, revealed the importance of this service, especially echography, to reduce concerns with their own and the fetus' health, and to enhance maternalfetal attachment. The mothers did demonstrate concern with the emotional demands of pregnancy, which according to them could not be considered in prenatal care.

Against expectations, the hypothesis of an association between women's mental health as assessed during pregnancy and sensitivity to the eight-month-old infant received little support in this study. A positive correlation was found between the total number of minor psychiatric disorder symptoms and the percentage of non-sensitive sequences to the infant's vocalizations only. Mothers with more symptoms of minor psychiatric disorders during pregnancy more frequently did not respond to the infant's vocalizations. Although this isolated result is hardly expressive from a statistical viewpoint, it is an important indicator that should be further explored in future studies. It is plausible to think that the mother's low sensitivity to the infant's vocalizations can affect not only child language development, but also the relation of mother and child in general, given the importance of vocalization for communication and social interactions.

No relation was found either between the postpartum depression score assessed during the infant's first month of life and the sensitivity dimensions that were investigated. In the regression analysis, both the minor psychiatric disorders scores during pregnancy and the depression scores during the first month did not explain variance in sensitivity scores. On the one hand, these findings underline some authors' assertion that the relation between maternal mental health and sensitivity is hardly consistent or that the findings are contradictory (Lovejoy et al., 2000; Wan \& Green, 2009). On the other hand, it is both premature and precipitated to affirm that this relation is not relevant, given the initial status of research in the area. Mediating or moderating variables like the chronic nature of depression and the presence of comorbidities, which were not assessed in this study, may explain these controversial findings in the future. In the study by Huang et al. (2012), chronic maternal depression was significantly associated with low maternal sensitivity. In that sense, future research involving clinical samples is fundamental, using instruments that permit a more precise assessment of maternal mental health or even the diagnosis of specific mental disorders. Anyway, research in community samples and screening instruments like the SRQ-20 and the BDI are also important, as they can clarify the extent to which the presence of symptoms of depression and other minor psychiatric disorders, even without a clinical diagnosis, can affect maternal sensitivity.

\section{Final Considerations}

In this study, the impact of maternal-fetal attachment on maternal sensitivity in the eighth month of life was confirmed. Due to the longitudinal design, which involved a time lag of about ten months between the assessment of these two factors, the predictive power of maternal-fetal attachment regarding maternal-infant interaction variables is highlighted. At the same time, the importance of interventions is emphasized to enhance affective bonding between mother and fetus, especially for women with mental disorders, but also for women going through difficulties during pregnancy, like living in a stressful environment, experiencing a health problem or having planned the pregnancy or not. Little support was found to confirm the hypothesis about the relation between the pregnant women's mental health and sensitivity but, in view of controversial findings in the literature and the present research limitations, further research is required to analyze these factors, using more complex designs and a more precise assessment of maternal mental disorders. In the specific case of postpartum depression, the use of the Edinburgh Postpartum Depression Scale is recommended, which has not been used in this study as the objective was to monitor maternal depression symptoms over a longer period, beyond the child's first year of life.

It is important to consider the limitations with regard to the assessment of sensitivity. Several authors have indicated the multidimensional nature of this construct and the possible repercussions of different measuring forms (Bornstein et al., 2008; Grusec \& Davidov, 2010). In this study, sensitivity was assessed during a free interaction episode, according to the analysis criteria of interval coding. Although the sensitivity construct is successfully put in practice in this assessment, it can obviously be improved or new measuring alternatives can be experimented to better detect qualitative differences in the appropriateness of maternal responses to infant behavior. Finally, other predictive variables that were not investigated in this study probably play a role in understanding sensitivity and could help to explain the variance in that factor, such as maternal personality (Prinzie et al., 2009), social support and the relation with the infant's father (Piccinini et al., 2007), as well as infant-related variables (Mills-Koonce et al., 2007; Thun-Hohenstein et al., 2008).

The findings about the impact of maternal sensitivity on different dimensions of infant development have been well established. In addition, the importance of the first two years of life and the quality of interactions during that period is a source of consensus in the international literature and takes the form of well-defined and systematic political and social strategies in different developed countries, especially with regard to so-called vulnerable communities. In that sense, efforts are essential to identify the main predictors of maternal sensitivity with a view to investing in interventions and social programs in Brazil, which direct or indirectly enhance motherinfant interaction and, consequently, child development. 


\section{References}

Ainsworth, M. D. S., Blehar, M. C., Waters, E., \& Wall, S. (1978). Patterns of attachment: A psychological study of the strange situation. Hillsdale, NJ: Lawrence Erlbaum.

Alvarenga, P., Dazzani, M. V. M., Alfaya, C. A. S., Lordelo, E. R., \& Piccinini, C. A. (2012). Relações entre a saúde mental da gestante e o apego maternofetal. Estudos de Psicologia (Natal), 17(3), 477-484. doi:10.1590/S1413-294X2012000300017

Alhusen, J. L., Gross, D., Hayat, M. J., Woods, A. B., \& Sharps, P. W. (2012). The influence of maternal-fetal attachment and health practices on neonatal outcomes in low-income, urban women. Research in Nursing \& Health, 35(2), 112-120. doi:10.1002/nur.21464

Belsky, J., \& Fearon, R. M. P. (2002). Early attachment security, subsequentmaternal sensitivity, andlaterchilddevelopment: Does continuity in development depend upon continuity of caregiving? Attachment \& Human Development, 4(3), 361-387. doi:10.1080/14616730210167267

Bornstein, M. H., Tamis-LeMonda, C. S., Hahn, C.-S., \& Haynes, O. M. (2008). Maternal responsiveness to young children at three ages: Longitudinal analysis of a multidimensional, modular, and specific parenting construct. Developmental Psychology, 44(3), 867-874. doi:10.1037/0012-1649.44.3.867

Bowlby, J. (1969). Attachment and loss: Vol. 1. Attachment. New York, NY: Basic Books.

Brandon, A. R., Pitts, S., Denton, W. H., Stringer, C. A., \& Evans, H. M. (2009). A history of the theory of prenatal attachment. Journal of Prenatal and Perinatal Psychology and Health, 23(4), 201-222.

Cerezo, M. A., Trenado, R. M., \& Pons-Salvador, G. (2012). Mother-infant interaction and quality of child's attachment: A nonlinear dynamical systems approach. Nonlinear Dynamics, Psychology, and Life Sciences, 16(3), 243-267.

Cranley, M. S. (1981). Development of tool for measurement of maternal attachment during pregnancy. Nursing Research 30(5), 281-284.

Cunha, J. A. (2001). Escalas Beck. São Paulo, SP: Casa do Psicólogo.

Feijó, M. C. C. (1999). Validação brasileira da "maternal-fetal attachment scale". Arquivos Brasileiros de Psicologia, 51(4), 52-62.

Fraley, R. C., Roisman, G. I., \& Haltigan, J. D. (2013). The legacy of early experiences in development: Formalizing alternative models of how early experiences are carried forward over time. Developmental Psychology, 49(1), 109-126. doi:10.1037/a0027852.

Gonçalves, D. M., Stein, A. T., \& Kapczinski, F. (2008). Avaliação de desempenho do Self-Reporting Questionnaire como instrumento de rastreamento psiquiátrico: Um estudo comparativo com o Structured Clinical Interview for DSM-IV-TR. Cadernos de Saúde Pública, 24(2), 380-390. doi:10.1590/S0102-311X2008000200017
Grusec, J. E., \& Davidov, M. (2010). Integrating different perspectives on socialization theory and research: A domain-specific approach. Child Development, 81(3), 687-709. doi:10.1111/j.1467-8624.2010.01426.x

Huang, Z. J., Lewin, A., Mitchell, S., \& Zhang, J. (2012). Variations in the relationship between maternal depression, maternal sensitivity, and child attachment by race/ethnicity and nativity: Findings from a nationally representative cohort study. Maternal Child Health Journal, 16(1), 40-50. doi:10.1007/s10995-010-0716-2

Isabella, R. A., Belsky, J., \& von Eye, A. (1989). Origins of infant-mother attachment: An examination of interactional synchrony during the infant's first year. Developmental Psychology, 25(1), 12-21. doi:10.1037/0012-1649.25.1.12

Koren-Karie, N., Oppenheim, D., Dolev, S., Sher, E., \& Etzion-Carasso, A. (2002). Mothers' insightfulness regarding their infants' internal experience: Relations with maternal sensitivity and infant attachment. Developmental Psychology, 38(4), 534-542. doi:10.1037/0012-1649.38.4.534

Landry, S. H., Smith, K. E., Swank, P. R., Assel, M. A., \& Vellet, S. (2001). Does early responsive parenting have a special importance for children's development or is consistency across early childhood necessary? Developmental Psychology, 37(3), 387-403. doi:10.1037/0012-1649.37.3.387

Landry, S. H., Smith, K. E., Swank, P. R., \& Guttentag, C. (2008). A responsive parenting intervention: The optimal timing across early childhood for impacting maternal behaviors and child outcomes. Developmental Psychology, 44(5), 1335-1353. doi:10.1037/a0013030

Lovejoy, M. C., Graczyk, P. A., O’Hare, E., \& Neuman, G. (2000). Maternal depression and parenting behavior: A meta-analytic review. Clinical Psychology Review, 20(5), 561-592. doi:10.1016/S0272-7358(98)00100-7

Lucassen, N., Tharner, A., Van IJzendoorn, M. H., Bakermans-Kranenburg, M., Volling, B. L., Verhulst, F. C., Lambregtse-Van den Berg, M. P., \& Tiemeier, H. (2011). The association between paternal sensitivity and infant-father attachment security: A meta-analysis of three decades of research. Journal of Family Psychology, 25(6), 986-992. doi:10.1037/a0025855.

Mercer, R. T. (2004). Becoming a mother versus maternal role attainment. Journal of Nursing Scholarship, 36(3), 226-232.

Mercer, R. T., \& Ferketich, S. L. (1994). Predictors of maternal role competence by risk status. Nursing Research, 43(1), 38-43.

Mills-Koonce, W. R., Gariépy, J.-L., Propper, C., Sutton, K., Calkins, S., Moore, G., \& Cox, M. (2007). Infant and parent factors associated with early maternal sensitivity: A caregiver-attachment systems approach. Infant Behavior and Development, 30(1), 114-126. doi:10.1016/j.infbeh.2006.11.010 
Moran, G., Forbes, L., Evans, E., Tarabulsy, G. M., \& Madigan, S. (2008). Both maternal sensitivity and atypical maternal behavior independently predict attachment security and disorganization in adolescent mother-infant relationships. Infant Behavior and Development, 31(2), 321-325. doi:10.1016/j.infbeh.2007.12.012

Nicol-Harper, R., Harvey, A. G., \& Stein, A. (2007). Interactions between mothers and infants: Impact of maternal anxiety. Infant Behavior and Development, 30(1), 161-167. doi:10.1016/j.infbeh.2006.08.005

Piccinini, C. A., Alvarenga, P., \& Frizzo, G. B. (2007). A responsividade como foco da análise da interação mãe-bebê e pai-bebê. In C. A. Piccinini \& M. L. S. Moura. (Orgs.), Observando a interação pais-bebê-criança (pp. 131-153). São Paulo, SP: Casa do Psicólogo.

Piccinini, C. A., Carvalho, F. T., Ourique, L. R., \& Lopes, R. S. (2012). Percepções e sentimentos de gestantes sobre o pré-natal. Psicologia: Teoria e Pesquisa, 28(1), 27-33. doi:10.1590/S0102-37722012000100004

Piccinini, C. A., Marin, A. H., Alvarenga, P., Lopes, R. C. S., \& Tudge, J. R. (2007). Responsividade materna em famílias de mães solteiras e famílias nucleares no terceiro mês de vida da criança. Estudos de Psicologia, 12(2), 109-117. doi:10.1590/S1413-294X2007000200002

Prinzie, P., Stams, G. J. J. M., Dekovic, M., Reijntjes, A. H. A., \& Belsky, J. (2009). The relations between parents' Big Five personality factors and parenting: A meta-analytic review. Journal of Personality and Social Psychology, 97(2), 351362. doi:10.1037/a0015823

Ribas, A. F. P., Moura, M. L. S., \& Ribas Junior, R. C. (2003). Responsividade materna: Levantamento bibliográfico e discussão conceitual. Psicologia: Reflexão e Crítica, 16(1), 137-145. doi:10.1590/S0102-79722003000100014

Santos, M. E. S. B. (2002). Transtornos mentais comuns em pacientes com AIDS que fazem uso de anti-retrovirais no Estado de São Paulo, Brasil (Unpublished master's thesis). Universidade de São Paulo, São Paulo, SP.

Schmidt, E. B., \& Argimon, I. I. L. (2009). Vinculação da gestante e apego materno fetal. Paidéia (Ribeirão Preto), 19(43), 211-220. doi:10.1590/S0103-863X2009000200009

Shin, H. J., Park, Y. J., \& Kang, H. C. (2004). Prediction model on mother-infant attachment during the early postpartum period [Abstract]. Taehan Kanho Hakhoe Chi, 34(3), 504-514.

Shin, H., Park, Y. J., \& Kim, M. J. (2006). Predictors of maternal sensitivity during the early postpartum period. Journal of Advanced Nursing, 55(4), 425-434.

Shin, H., Park, Y. J., Ryu, H., \& Seomun, G. A. (2008). Maternal sensitivity:Aconcept analysis. Journal of Advanced Nursing, 64(3), 304-314. doi:10.1111/j.1365-2648.2008.04814.x

Siddiqui, A., \& Hagglof, B. (2000). Does maternal prenatal attachment predict postnatal mother-infant interaction? Early Human Development, 59(1), 13-25. doi:10.1016/S0378-3782(00)00076-1
Stern, D. N. (1997). A constelação da maternidade. Porto Alegre, RS: Artes Médicas.

Thun-Hohenstein, L., Wienerroither, C., Schreuer, M., Seim, G., \& Wienerroither, H. (2008). Antenatal mental representations about the child and mother-infant interaction at three months post partum. European Child \& Adolescent Psychiatry, 17(1), 9-19. doi:10.1007/s00787-007-0622-3

Vandell, D. L., Belsky, J., Burchinal, M., Steinberg, L., Vandergrift, N., \& the NICHD Early Child Care Research Network. (2010). Do effects of early child care extend to age 15 years? Results from the NICHD Study of Early Child Care and Youth Development. Child Development, 81(3), 737-756. doi:10.1111/j.1467-8624.2010.01431.x

Yarcheski, A., Mahon, N. E., Yarcheski, T. J., Hanks, M. M., \& Cannella, B. L. (2009). A meta-analytic study of predictors of maternal-fetal attachment. International Journal of Nursing Studies, 46(5), 708-715. doi:10.1016/j.ijnurstu.2008.10.013

Wakschlag, L. S., \& Hans, S. L. (1999). Relation of maternal responsiveness during infancy to the development of behavior problems in high-risk youths. Developmental Psychology, 35(2), 569-579. doi:10.1037/0012-1649.35.2.569

Wan, M. W., \& Green, J. (2009). The impact of maternal psychopathology on child-mother attachment. Archives of Women's Mental Health, 12(3), 123-134. doi:10.1007/s00737-009-0066-5

Waxler, E., Thelen, K., \& Muzik, M. (2011). Maternal perinatal depression: Impact on infant and child development. US Obstetrics \& Gynecology, 6(2), 96-102.

Patricia Alvarenga is a faculty member at Universidade Federal da Bahia.

Maria Virginia Machado Dazzani is a faculty member at Universidade Federal da Bahia.

Cristiane Ajnamei dos Santos Alfaya is a faculty member at Universidade Federal do Recôncavo da Bahia.

Eulina da Rocha Lordelo is a retired faculty member at Universidade Federal da Bahia.

César Augusto Piccinini is a faculty member at Universidade Federal do Rio Grande do Sul.

Received: Jul. $16^{\text {th }} 2012$

$1^{\text {st }}$ Revision: Dec. $6^{\text {th }} 2012$

$2^{\text {nd }}$ Revision: Mar. $7^{\text {th }} 2013$

Approved: Apr. $1^{\text {st }} 2013$

\section{How to cite this article:}

Alvarenga, P., Dazzani, M. V. M., Alfaya, C. A. S., Lordelo, E. R., \& Piccinini, C. A. (2013). Predictors of sensitivity in mothers of 8-month-old infants. Paidéia (Ribeirão Preto), 23(56), 311-319. doi:10.1590/1982-43272356201305 


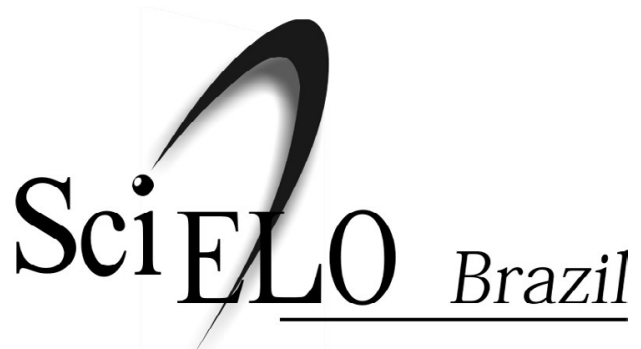

The SciELO interface provides easy access to the tables of content and to the full-text articles.

The SciELO interface also provides the retrieval of articles by the author's name, the words from title, abstract and descriptors, in addition to providing bibliometric indicators and consultation indicators.

The articles are enriched with connections to the LILACS, MEDLINE and PubMed databases.

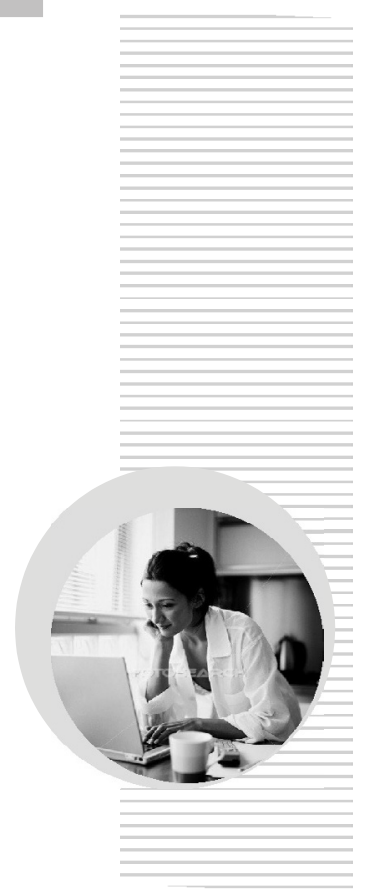

Paidéia (Ribeirão Preto) is a part of SciELO Brazil:

\section{www.scielo.br/paideia}

The SciELO interface provides access to a network of SciELO websites, gathering the major scientific journals of Latin America, Caribbean, Spain, Portugal and South Africa:

\section{www.scielo.org}

The electronic library is a project developed by the São Paulo Research Fundation (FAPESP), in partnership with the Latin American and Caribbean Center on Health Sciences Information (BIREME) and the National Council for Scientific and Technological Development (CNPq). 